\title{
Sub-Synchronous Range of Operation for a Wind Driven Double-Fed Induction Generator
}

\author{
Mahmoud Abdel Halim Saleh ${ }^{\dagger}$ and Mona Naguib Eskander* \\ †* Power Electronics \& Energy Conversion Dept., Electronics Research Institute, Cairo, Egypt
}

\begin{abstract}
In this paper the operation of a double-fed wound-rotor induction machine, coupled to a wind turbine, as a generator at sub-synchronous speeds is investigated. A novel approach is used in the analysis, namely, the rotor power flow approach. The conditions necessary for operating the machine as a double-fed induction generator (DFIG) are deduced. Formulae describing the factors affecting the range of sub-synchronous speeds within which generation occurs are deduced. The variations in the magnitude and phase angle of the voltage injected to the rotor circuit as the speed of the machine changes to achieve generation at the widest possible sub-synchronous speed range is presented. Also, the effect of the rotor parameters on the generation range is presented. The analysis proved that the generation range could increase from sub-synchronous to super- synchronous speeds, which increases the amount of energy captured by the wind energy conversion system (WECS) as result of utilizing the power available in the wind at low wind speeds.
\end{abstract}

Key Words: Double fed induction machine, Grid-connection, Power generation, Wind energy

\section{INTRODUCTION}

The penetration of large scale wind energy conversion systems (WECS) into electrical power grids has been growing rapidly in recent years. The installed capacity of WECS reached $121 \mathrm{GW}$ by the end of 2008 , with a growth rate of about $30 \%$ annually [1]. This high growth rate is mainly due to the many environmental, technical and economic merits of wind energy technologies. The environmental reasons for preferring wind energy over fossil fuel are its plentiful, renewable and widely distributed nature, along with the fact that they do not produce greenhouse gases. Technical and economic merits are manifested in the development of design methodologies, new materials, and manufacturing technologies which enabled the production of more robust, less vibrating large wind turbines at a lower cost.

Also, tremendous improvements in solid state power conversion technologies allow the use of variable speed WECS that utilize various converters (static converters, cycloconverters, matrix converters, etc.) to generate power at a constant frequency. This ensures their technical viability and economic feasibility.

It is well known that wind turbines must generate at all power levels and that they spend a substantial amount of time at low power levels [2]. Unlike most electrical generators, wind generators must operate at the highest possible aerodynamic

Manuscript received May 14, 2009; revised Oct. 27, 2009

$\dagger$ Corresponding Author: eskander@eri.sci.eg

Tel: +202-33310553, Fax: +202-33351631, Electronics Research Institute

* Power Electronics \& Energy Conversion Dept., Electronics Research

Institute, Egypt and electrical efficiency in low-power/low-wind speed regimes to extract the maximum amount of energy from the available wind.

Recently, newly installed WECS use double fed induction generators (DFIG) due to their variable speed nature. The DFIGs are coupled with adjustable speed wind turbines with power in the mega-watt range. Adjustable speed wind generators (ASG) have many advantages compared to fixed speed generators (FSG). Among these advantages are cost effectiveness and simple pitch control. This is because at lower speeds, the pitch angle is usually fixed and pitch angle control is performed only to limit the output power at wind speeds higher than the rated speed. ASGs can also reduce mechanical stresses because gusts of wind can be absorbed. They also reduce torque pulsations, and dynamically compensate for torque and power pulsations caused by back pressure from the tower. Reduction of the torque pulsations improves power quality and hence eliminates electrical power variations that cause flickers. In ASGs turbine speed is adjusted as a function of wind speed to maximize the turbine output power, thus improving the system efficiency.

A variable speed wind turbine coupled to a double fed induction generator (DFIG) with its rotor circuit connected to the power grid via a converter has many advantages when compared to constant speed WECS. First, only the electrical power injected to the rotor needs to be handled by the converter, implying a lower cost for the converter. Secondly, there is improved system efficiency due to the smaller size of the converter. Hence, an ASG equipped with a DFIG is one of the most efficient configurations for wind energy conversion. 
In this paper, the sub-synchronous speed operation of a DFIG, coupled to an adjustable speed wind turbine, is investigated. The stator of the DFIG is connected to the power grid (directly or via a transformer) and its rotor is connected to the power grid via a converter and possibly a transformer. The rotor circuit is fed from the converter with a voltage at the slip frequency and with an adjustable magnitude and phase angle which are varied as the turbine speed changes. This is done in order to maximize the energy captured from the wind at the lowest possible wind speeds (from the cut-in speed to the rated speed).

Most, if not all, of the published papers on the subject analyze the performance of DFIG using the $\mathrm{d}-\mathrm{q}$ axes theory [3-7]. However, in this paper another approach is used which is the power flow approach. In this approach the interrelations among the rotor power (slip power $s P_{g}$ ), the air gap power $P_{g}$ and the mechanical power Pm are used to determine the magnitude and phase of the injected voltage to the rotor circuit for which a certain induction machine will operate as a generator within a certain specified speed range below the synchronous speed. Also, the injected voltage phase angle for which the DFIG can produce maximum power at a certain specified magnitude of this voltage is determined. In addition, the optimum control strategy for a static converter feeding the rotor of a DFIG coupled to a variable speed wind turbine is deduced and reflected in a set of curves to facilitate WECS design.

\section{Determination of the Sub-Synchronous RANGE FOR A DFIG}

In general an induction machine has three operating modes, namely the motor, the generator and the brake modes. The power flowing in the rotor of a slip-ring induction machine (i.e. of the wound rotor type) has three main components. These are a) the electromagnetic power transferred between the stator and the rotor through the air gap which is known as the air gap power $P_{g}$; b) the mechanical power $P_{m}$ transferred between the rotor and the shaft; c) the slip power $P_{r}$ which is transferred between the rotor and any external electrical source or load (e.g. a converter) through the rotor slip-rings and/or consumed in the rotor winding as copper losses $\left(P_{r}=\right.$ $P_{c}+P_{c u r}$, where $P_{c}$ is the converter output/input power and $P_{c u r}$ is the rotor copper losses). The three components of rotor power are interrelated, under any conditions, as follows:

$$
\begin{aligned}
& P_{g}=P_{m}+P_{r}=(1-s) P_{g}+s P_{g} \\
& P_{m}=(1-s) P_{g} \\
& P_{r}=s P_{g}
\end{aligned}
$$

where the slip $s=\left(n_{s}-n\right) / n_{s}$.

The first known induction machine was a motor with short circuited rotor windings and running at a speed lower than its synchronous speed. The mechanical power $P_{m}$ is considered positive when transferred from the rotor to the shaft and then to the mechanical load. In this case $(0<s<1)$, the air gap power which is transferred from the stator to the rotor will be positive. If the direction of flow for both $P_{g}$ and $P_{m}$ is reversed (i.e. $P_{g}$ and $P_{m}$ have negative values) the machine will operate in the generator mode. The slip power will also be negative, i.e. it will be supplied by the converter to the rotor, if $0<s<1$. But if $s<0$, the slip power will be positive, i.e. it will be transferred from the rotor to the converter and back to the grid. Using the same logic, the other modes are defined.

Table 1 summarizes the different operating modes of a slip-ring induction machine. The positive and the negative signs indicate the direction of flow for the different power components for each mode. Needless to say, the air gap power $P_{g}$ is equal to the stator input (output) power minus (plus) the stator copper and the machine iron losses. The mechanical power Pm is equal to the net mechanical output (input) on the shaft plus (minus) the friction and windage losses. Also, the slip power $s P_{g}$ is equal to the electric power returned back to (extracted from) the converter plus (minus) the rotor copper losses. Concerning the electric power returned back to (extracted from) the grid, the losses in the converter and the transformer connected to it, if any, should be added (subtracted). Accordingly the configuration of a DFIG static converter scheme is shown in Fig. 1.

The terminal voltage $\mathbf{V}_{\mathbf{c}}$ of the converter is of variable frequency, magnitude and phase. The frequency of $\mathbf{V}_{\mathbf{c}}$ is controlled to be equal to the frequency of the induced rotor voltage $\mathbf{E}_{\mathbf{r}}$. At the steady state, let $\mathbf{E}_{\mathbf{r}}$ be the reference phasor:

$$
\mathbf{E}_{\mathbf{r}}=E_{r} e^{j 0}=E_{r}
$$

Hence the phase voltage $\mathbf{V}_{\mathbf{c}}$ is written as:

$$
\mathbf{V}_{\mathbf{c}}=V_{c} e^{j \gamma}=V_{c}(\cos \gamma+j \sin \gamma)
$$

The total voltage in the rotor circuit is:

$$
\mathbf{E}_{\mathbf{r}}-\mathbf{V}_{\mathbf{c}}=E_{r}-V_{c}(\cos \gamma+j \sin \gamma)
$$

If the rotor resistance is $R_{r}$ and the rotor leakage reactance at standstill is $X_{r}$, then the rotor current at any slip s is given by:

$$
\mathbf{I}_{\mathbf{r}}=\frac{E_{r}-V_{c}(\cos \gamma+j \sin \gamma)}{R_{r}+j s X_{r}}
$$

The voltage induced in the rotor circuit at any slip " $s$ " is given as:

$$
E_{r}=s . E_{r o}
$$

where $E_{r o}$ is the magnitude of the rotor induced voltage at standstill per phase with open circuited rotor windings.

Hence eq. (4) is rewritten as:

$$
\mathbf{I}_{\mathbf{r}}=\frac{s E_{r_{o}}-V_{c}(\cos \gamma+j \sin \gamma)}{R_{r}+j s X_{r}}
$$

Let the ratio of the magnitude of the converter voltage to that of the induced rotor voltage at standstill be $\alpha\left(\alpha=V_{c} / E_{r_{o}}\right)$, then:

$$
\mathbf{I}_{\mathbf{r}}=\frac{E_{r o}}{R_{r}} \frac{s-\alpha \cos \gamma-j \alpha \sin \gamma}{1+j s \beta}
$$


TABLE I

POWER FLOW IN THE ROTOR FOR DIFFERENT MODES OF OPERATION \& DIFFERENT ROTOR SPEEDS

\begin{tabular}{|l|c|c|c|c|c|}
\hline Mode & $\begin{array}{c}\text { Motor } \\
\text { Subsynch }\end{array}$ & $\begin{array}{c}\text { Motor } \\
\text { Supersynch }\end{array}$ & $\begin{array}{c}\text { Generator } \\
\text { Supersych }\end{array}$ & $\begin{array}{c}\text { Generator } \\
\text { Subsynch }\end{array}$ & Brake \\
\hline Slip $s$ & $0<s<1$ & $s<0$ & $s<0$ & $0<s<1$ & $s>1$ \\
\hline Airgap power $P_{g}$ & positive & positive & negative & negative & positive \\
\hline Mechanical power $P_{m}$ & positive & positive & negative & negative & negative \\
\hline Slip power $s P_{g}$ & positive & negative & positive & negative & positive \\
\hline
\end{tabular}

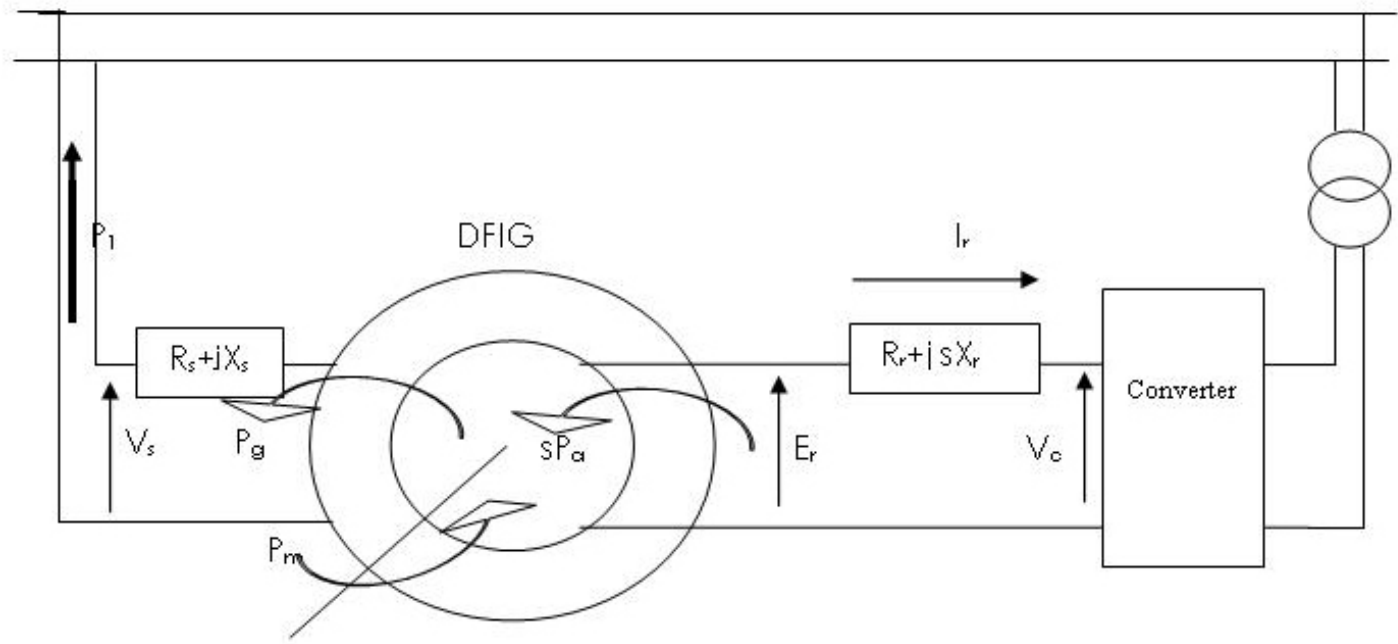

Fig. 1. Double fed induction generator for sub-synchronous speed.

where $\beta=X_{r} / R_{r}$, i.e. the ratio of the rotor leakage reactance at standstill to the rotor resistance.

Manipulating eq. (7) yields:

$$
\begin{aligned}
\mathbf{I}_{\mathbf{r}}= & \frac{E_{r_{o}}}{R_{r}} \frac{[(s-\alpha \cos \gamma)-j \alpha \sin \gamma](1-j s \beta)}{I+s^{2} \beta^{2}} \\
\mathbf{I}_{\mathbf{r}}= & \frac{E_{r_{o}}}{R_{r}\left(1+s^{2} \beta^{2}\right)}[(s-\alpha \cos \gamma-s \alpha \beta \sin \gamma) \\
& -j\left(\alpha \sin \gamma+s^{2} \beta-s \alpha \beta \cos \gamma\right]
\end{aligned}
$$

The rotor power (slip power) is given as:

$$
s P_{g}=\operatorname{Re}\left(m \mathbf{E}_{\mathbf{r}} \mathbf{I}^{*} \mathbf{r}\right),
$$

where $m$ is the number of phases and Re is the real part.

The air gap power is given as:

$$
P_{g}=\frac{m E_{r o}^{2}}{R_{r}\left(1+s^{2} \beta^{2}\right)}(s-\alpha \cos \gamma-s \alpha \beta \sin \gamma)
$$

where $P_{g}$ is the electromagnetic power transferred between the stator and the rotor of the induction machine according to its operation as a motor or a generator.

The known equation for air gap power is:

$$
P_{g}=P_{1} \mp P_{L}
$$

where $P_{1}$ is the stator input/output power and $P_{L}$ is the stator copper losses and iron losses of the machine.

A positive $P_{g}$ indicates the transfer of power from stator to rotor, and vise versa. Hence for the induction machine to operate as generator at any sub-synchronous speed $(0<s<$ 1), $P_{g}$ must be negative at this slip.

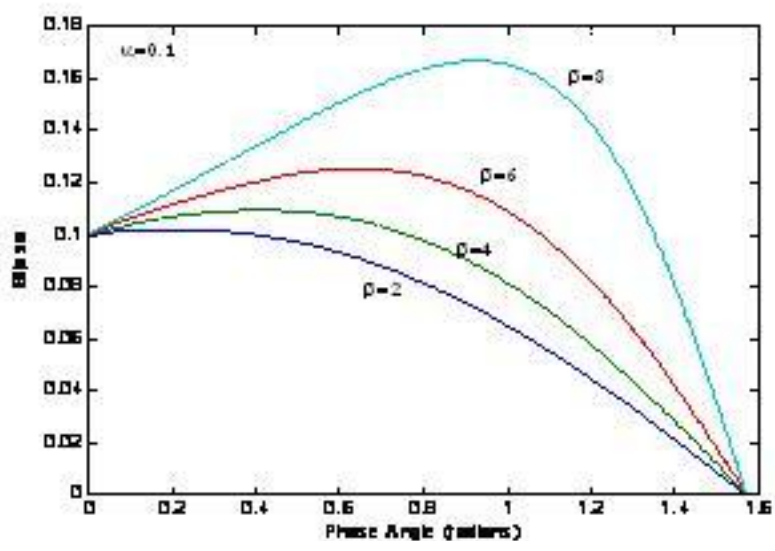

Fig. 2. Slip range for sub-synchronous generation at $10 \%$ injected voltage.

From eq. (11), $P_{g}$ will be negative under the following conditions:

$$
(s-\alpha \cos \gamma-s \alpha \beta \sin \gamma)<o
$$

Consequently for generation:

$$
s<s_{o}=\frac{\alpha \cos \gamma}{1-\alpha \beta \sin \gamma}
$$

Therefore, the induction machine will operate as a generator at sub-synchronous speeds within the slip range $0<s<s_{o}$, where $s_{o}$ is the slip above which the flow of the air gap power (and electromagnetic torque) changes its direction. 


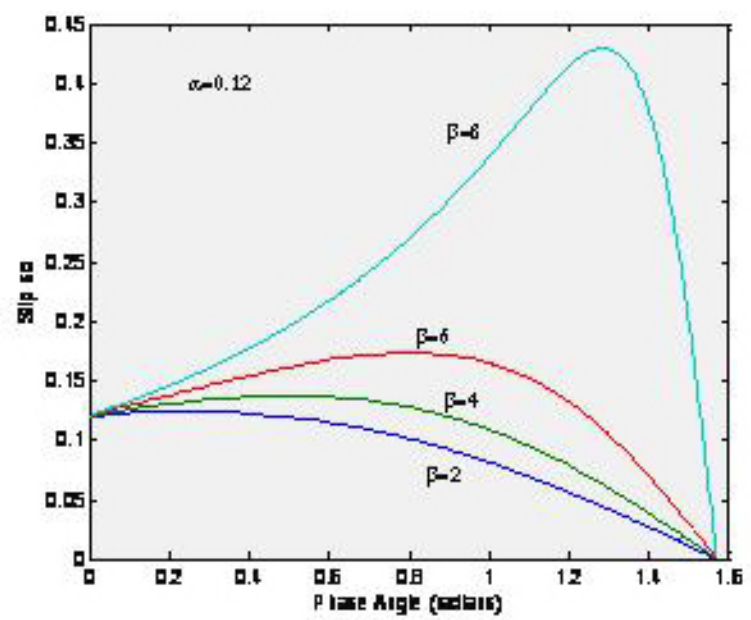

Fig. 3. Slip range for sub-synchronous generation at $12 \%$ injected voltage.

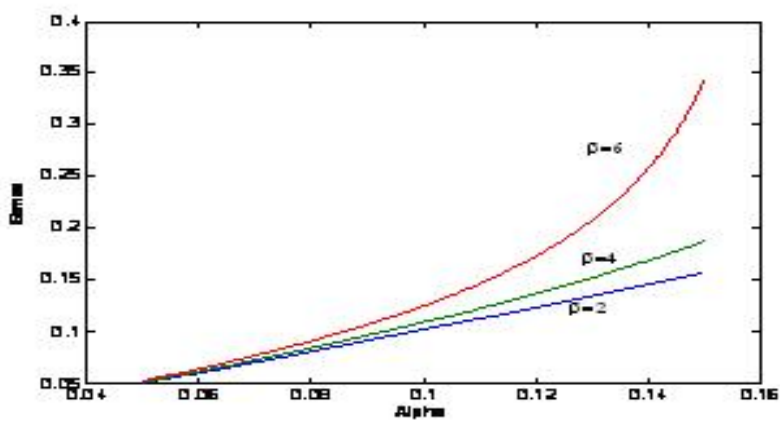

Fig. 4. Variation of maximum speed range for sub-synchronous generation with magnitude of injected voltage.

Fig. 2 and 3 show the variations of $s_{o}$ as a function of the phase angle $\gamma$ for different values of $\beta(\beta=2,4,6$, 8 ), and for different values of the magnitude of the injected voltage $V_{c}(\alpha=0.1,0.12)$. It is clear from these figures that all the parameters; $\alpha, \beta$, and $\gamma$, affect the value of $s_{o}$. With an increase of either $\alpha$ or $\beta$, the sub-synchronous generation range is increased. However, the phase of the injected voltage $V_{c}$ has a different effect on the sub-synchronous generation range. It is worth noticing that under the same conditions, a phase angle $\gamma$ exists at which the generation range at subsynchronous speed is at its maximum. The curve of the air gap power (or electromagnetic torque) versus the slip is shifted to the right as $\alpha$ or $\gamma$ are changed. This shift differs from one machine to another depending on the value of $\beta$.

The maximum value of the slip $\left(s_{0 \max }\right)$ is obtained by differentiating $s_{o}$ with respect to $\gamma$ and equating the derivative to zero. This gives:

$$
\left.\sin \gamma\right|_{\text {somax }}=\alpha \cdot \beta
$$

and,

$$
s_{\text {omax }}=\frac{\alpha}{\sqrt{1-\alpha^{2} \beta^{2}}}
$$

The dependence of $s_{\text {omax }}$ on the value of the injected voltage is shown in Fig. 4. Fig. 5 shows $s_{\text {omax }}$ as a function of $\beta$ for different values of $\alpha(0.05-0.15)$. It is clear from Fig.

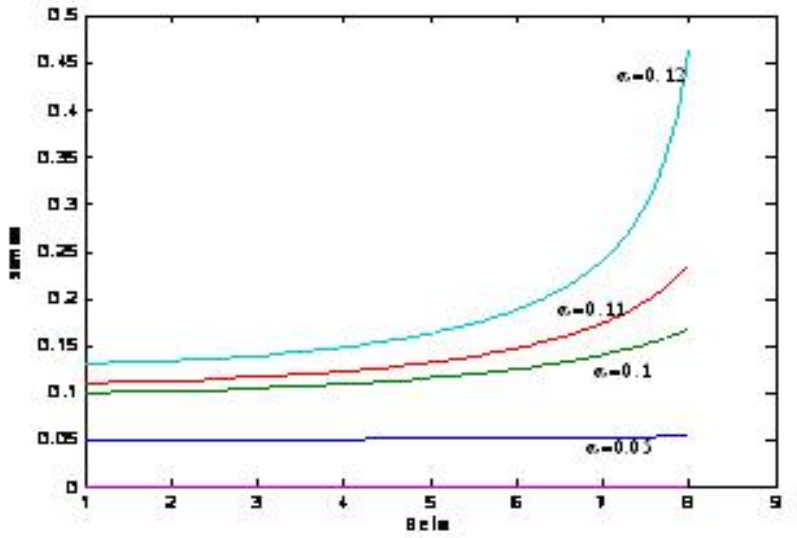

Fig. 5. Maximum slip range at sub-synchronous generation for any DFIG.

5 that for a large size induction machine with larger values of $\beta$ (MW range), the range of sub-synchronous speed within which generation occurs is wider. Also, this range increases with increasing $V_{c}$ but within a limit that prevents increasing the machine current over its rated value. However this range may be increased by proper selection of the angle $\gamma$.

The set of curves in Fig. 5 should be very helpful to a wind energy conversion system designer. Having the specifications for the different components of a WECS, the system designer can quickly judge to which extent these components match the requirements of the system by using this set of curves.

\section{Optimum Air GAP POWER}

Considering eq. (11) the magnitude of the air gap power is a function of different factors. Some of these factors are the design parameters $\left(E_{r o}, R_{r}\right.$ and $\left.\beta\right)$, while others are determined by external factors; the wind speed and consequently the turbine and generator rotational speed or slip. The two parameters that control the value of the air gap power are the magnitude $\alpha$ and the phase angle $\gamma$ of the rotor injected voltage. The air gap power is a linear function of $\alpha$, i.e. any increase in $\alpha$ increases $P_{g}$. The only limit to this increase is the rotor current value to prevent the machine from overheating. However, by adjusting the phase angle $\gamma$ for each value of the rotor injected voltage $V_{c}$, maximum power can be transferred from the rotor to the stator of the induction machine and hence to the grid. The value of this maximum power can be obtained by differentiating eq. (11) with respect to $\gamma$ and equating the derivative to zero:

$$
\frac{\partial P_{g}}{\partial \gamma}=\alpha \sin \gamma-s \alpha \beta \cos \gamma=0
$$

Therefore maximum $P_{g}$ takes place at:

$$
\gamma=\arctan (s \beta)
$$

In WECS the value of $\beta$ is a design parameter of the machine, while the slip is determined by the wind speed. Substituting $\gamma$ from eq. (17) into $P_{g}$, yields the following expression for the maximum air gap power and consequently 


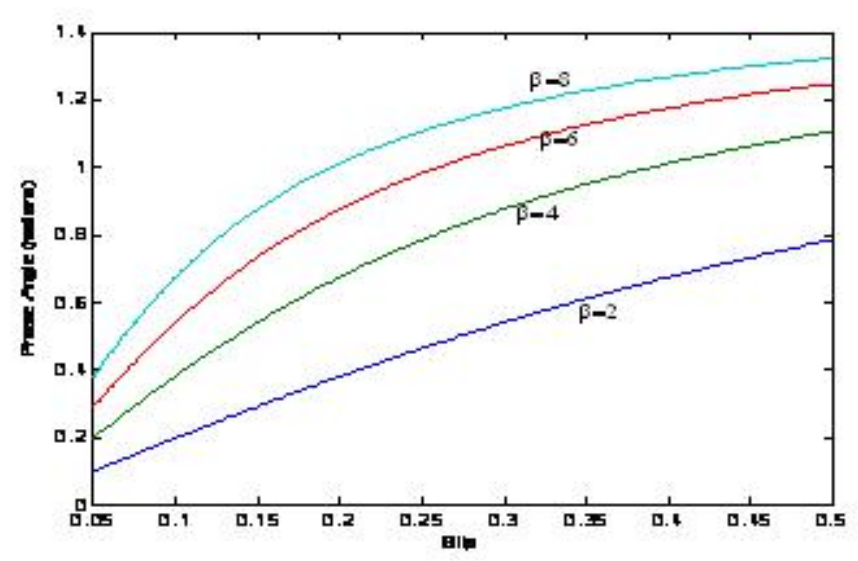

Fig. 6. Variation of phase angle of the injected voltage corresponding to maximum air gap power with slip.

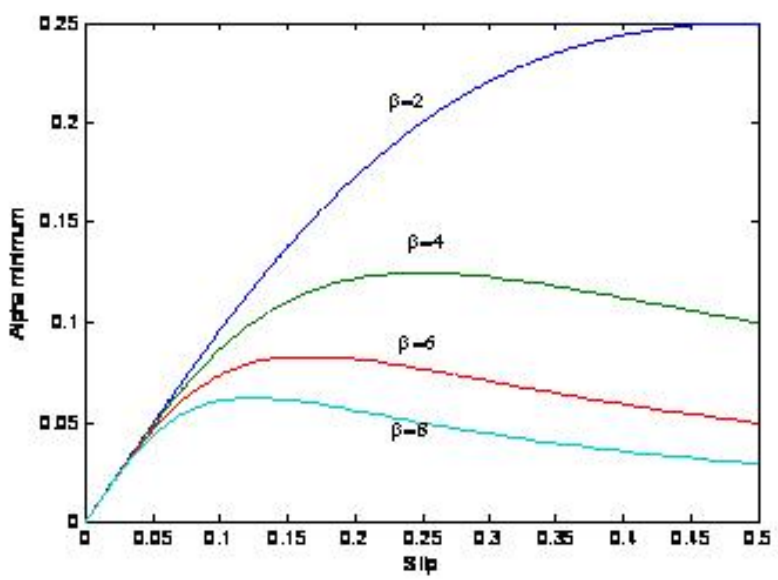

Fig. 7. Variation of minimum value of the injected voltage above which generation occurs.

the maximum power output of the DFIG for a certain $\alpha$ :

$$
\begin{aligned}
P_{g_{\max }} & =\frac{m E_{r o}^{2}}{R_{r}\left(1+s^{2} \beta^{2}\right)}\left[s-\alpha \cos \gamma-\alpha \frac{\sin ^{2} \gamma}{\cos \gamma}\right] \\
& =\frac{m E_{r o}^{2}}{R_{r}\left(1+s^{2} \beta^{2}\right)}\left[s-\frac{\alpha}{\cos \gamma}\right]
\end{aligned}
$$

Giving:

$$
P_{g_{\max }}=\frac{m E_{\text {ro }}^{2}}{R_{r}\left(1+s^{2} \beta^{2}\right)}\left[s-\alpha \sqrt{1+s^{2} \beta^{2}}\right]
$$

Needless to say, for generation to take place, $\alpha$ must not be less than:

$$
\begin{aligned}
& \frac{s}{\sqrt{1+s^{2} \beta^{2}}} \\
& \text { i.e., } \quad \alpha>\frac{s}{\sqrt{1+s^{2} \beta^{2}}}
\end{aligned}
$$

The values of $\gamma$ for maximum $P_{g}$ are plotted versus $s$ at different values of $\beta$ in Fig. 6 .

The minimum value of $\alpha$ below which no generation occurs at sub-synchronous speed is plotted versus $s$ for different values of $\beta$ in Fig. 7. The results show higher power generation at higher values of $\beta$. Since large induction machines usually have high values of $\beta(\beta>4)$, it is expected that these machines operate as generators at sub-synchronous speeds with a rotor injected voltage that is $\leq 25 \%$ of the standstill rotor induced voltage, down to a slip of 0.5 . The only requirement is adjusting the phase angle $\gamma$ of the injected voltage to be equal to $\arctan (s \beta)$.

The nominal power of a machine is calculated during the design phase as being the machine output when the rotor is short circuited, i.e. $\alpha=0$, hence:

$$
P_{g n}=\frac{m E_{r o}^{2}}{R_{r}\left(1+s_{n}^{2} \beta^{2}\right)} \cdot s_{n}
$$

where $P_{g n}$ is the nominal power and $s_{n}$ is the nominal slip, hence:

$$
\frac{P_{g}}{P_{g_{n}}}=\frac{1+s_{n}^{2} \beta^{2}}{1+s^{2} \beta^{2}}\left[\frac{s}{s_{n}}(1-\alpha \beta \sin \gamma)-\frac{\alpha}{s_{n}} \cos \gamma\right]
$$

Usually $s_{n}<<1$, and consequently, $s_{n}^{2} \beta^{2}<<1$, hence the per unit value of the maximum air gap power is:

$$
P_{g_{\text {max } p u}} \cong \frac{1}{1+s^{2} \beta^{2}}\left[\frac{s}{s_{n}}-\frac{\alpha}{s_{n}} \sqrt{1+s^{2} \beta^{2}}\right]
$$

\section{DFIG Coupled to A Wind Turbine}

A WT has four operating regions. In the first region the WT speed is less than the cut-in speed, so no power is generated. In the second region, the WT speed lies between the cut-in speed and the rated speed, which is the region of sub-synchronous operation of a DFIG investigated in this paper. Usually the rated speed of a WT corresponds to the synchronous speed of a DFIG. In the third region, the DFIG rotates with supersynchronous speed up to the cut-out speed. In the fourth region the WT speed exceeds the cut-out speed, and the turbine is shut down to avoid excessive mechanical stress on the turbine blades.

The typical output power of an ideal WT varies with the cube of the wind speed and consequently the mechanical power of the DFIG coupled to the WT theoretically varies with the cube of its rotor speed.

This power versus wind speed characteristic is the goal of WT designers within economical and structural constraints. The practical characteristic is different, i.e. the WT produces power above a given wind speed (cut-in speed). The shape of the power versus wind speed characteristic between the cutin speed and the rated speed may take any shape, e.g. linear, quadratic, cubic, and even higher powers. It may also be a combination of all these shapes [8]. The quadratic shape is generally adopted in practice. Hence in the region investigated in this paper, where $s_{c}<s<s_{r}$, the WT output power is assumed to be proportional to the square of the rotor speed. The mechanical output power of the WT, which is the input power to the DFIG, is expressed as function of the slip:

$$
P_{m}=K\left(1-s / s_{c}\right)^{2}
$$

where $s_{c}$ and $s_{r}$ correspond to the cut-in and the rated speeds, respectively.

The nominal speed of the DFIG $\left(n_{n}\right)$, is usually equal to the rated speed of the WT $\left(n_{r}\right)$, and it is very close to the 


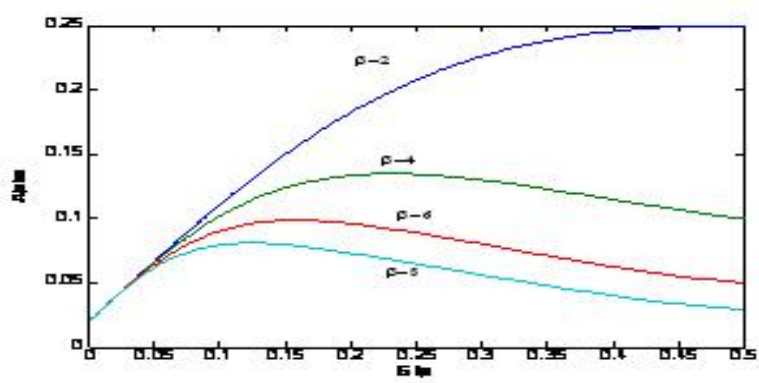

Fig. 8. Appropriate magnitude of voltage injected to the rotor of a DFIG coupled to WT for optimum power generation.

synchronous speed of the DFIG

(i.e. $n_{n}=n_{r} \cong n_{s}$, or $s_{n} \cong s_{r} \cong o$ )

The mechanical power of the WT, which is input to the DFIG, is related to the air gap power as:

$$
-P_{m}=-(1-s) P_{g}
$$

Combining eq. (21) and (24) and substituting $\gamma=$ $\arctan (s \beta)$, noting that $P_{m n} \cong P_{g n}$, the following equation is obtained:

$\left(1-\frac{s}{s_{c}}\right)^{2}=-(1-s) \frac{1}{1+s^{2} \beta^{2}}\left[\frac{s}{s_{n}}-\frac{\alpha}{s_{n}} \sqrt{1+s^{2} \beta^{2}}\right]$

Eq. (25) gives the minimum magnitude of injected rotor voltage (or voltage ratio $\alpha$ ), that ensures full conversion of the turbine mechanical output power, minus the friction and windage losses, into electrical power provided that the phase angle $\gamma=\arctan (s \beta)$.

It should be mentioned that the WT provides the DFIG with mechanical power while the electric grid supplies power to the rotor circuit via the static converters connecting the DFIG rotor with the grid. These converters supply the power at slip frequency. The supplied rotor power and the input mechanical power are transferred via the DFIG air gap to its stator then to the electrical grid at the grid frequency.

From eq. (25), the value of $\alpha$ is given by:

$$
\alpha=\frac{s}{\sqrt{1+s^{2} \beta^{2}}}+\frac{s_{n}}{1-s}\left(1-\frac{s}{s_{c}}\right)^{2} \sqrt{1+s^{2} \beta^{2}}
$$

The appropriate applied voltage magnitude as function of slip for different values of $\beta$ is shown in Fig. 8 for a wind turbine with an output power proportional to the square of the wind speed from the cut-in to the rated speed.

\section{Control Strategy For a Wind Driven DFIG}

Consider a 3-phase, $1000 \mathrm{~kW}, 6 \mathrm{kV}$, slip ring induction machine used as a DFIG with the following nameplate: 32 poles, star-star connected, $50 \mathrm{~Hz}, 2 \%$ nominal slip, $R_{s}=0.45 \Omega /$ phase, $X_{s}=3.15 \Omega /$ phase, $R_{r}=0.0194 \Omega /$ phase, $X_{r}=0.147 \Omega /$ phase, $X_{m}=58.9 \Omega /$ phase, effective stator to rotor turns ratio $=5.874$.

The DFIG is driven by a $1 \mathrm{MW}$ wind turbine with a $5 \mathrm{~m} / \mathrm{sec}$ cut-in speed and an $11 \mathrm{~m} / \mathrm{sec}$ rated speed. The output power of the WT varies as the square of the wind speed from the cut-in to the rated speed. The rotor circuit of the DFIG is connected to a static converter. The controller applied to the converter adjusts the magnitude, the frequency and the time lead of the voltage applied to the rotor according to a predetermined control strategy. The control strategy is based on a measurement of the magnitude, the phase and the frequency of the rotor induced voltage, or a measurement of the rotor speed and the power angle.

Using fig. 4 and 5 or eq. (14) and (15), noting that $\beta=$ 7.577 , the control strategy can be applied from the following look-up table:

TABLE II

CONTROL STRATEGY LOOK-UP TABLE

\begin{tabular}{|l|l|l|l|l|l|l|l|l|l|}
\hline$s$ & .05 & 0.1 & .15 & .2 & .25 & .3 & .35 & .4 & .5 \\
\hline$\alpha$ & .066 & .0976 & .1165 & .127 & .13 & .131 & .130 & .129 & .127 \\
\hline$\gamma($ rad. $)$ & 0.362 & 0.65 & 0.85 & 0.987 & 1.08 & 1.155 & 1.21 & 1.25 & 1.311 \\
\hline$f_{c}(\mathrm{~Hz})$ & 2.5 & 5 & 7.5 & 10 & 12.5 & 15 & 17.5 & 20 & 25 \\
\hline$V_{c}(\mathrm{v})$ & 229 & 338.6 & 404 & 441 & 451 & 455 & 451 & 448 & 441 \\
\hline$t_{c}(\mathrm{~ms})$ & 23.1 & 20.64 & 18.04 & 15.71 & 13.81 & 12.27 & 11.01 & 9.96 & 8.36 \\
\hline
\end{tabular}

where $t_{c}=$ time lead of the voltage $V_{c}$ with respect to the rotor induced voltage $E_{r}$.

To ensure that the selected values of $\alpha$ and $\gamma$ at a given slip allow operation of the DFIG in stable range, the $s_{m}<<s_{o}$.

$s_{m}$ is the slip at which the air gap power is at a maximum for specific values of $\alpha$ and $\beta$. The value of $s_{o}$ was deduced previously while the value of $s_{m}$ could be deduced by differentiating the equation of $P_{g}$ with respect to s and equating the derivative to zero.

$$
\delta P_{g} / \delta s=1-s_{m}^{2} \beta^{2}+2 s_{m} \alpha \cdot \beta^{2}(\cos \gamma / 1-\alpha \beta \cdot \sin \gamma)
$$

By solving this quadratic equation for $s_{m}$ and substituting $s_{o}=[\alpha \cos \gamma /(1-\alpha \beta \cdot \sin \gamma)]$ the following expression is obtained for the generating mode

$$
s_{m}=s_{o}\left(\sqrt{ } 1+s_{o}^{2} \cdot \beta^{2}\right) / \beta
$$

When using the values for $\alpha$ and $\gamma$ from Table (2), then for each value of $\mathrm{s}$ the corresponding values of $s_{o}$ and $s_{m}$ are given in table (3).

TABLE III

SLIP VALUES CORRESPONDING TO GENERATION \& STABLE RANGES OF OPERATION

\begin{tabular}{|l|l|l|l|l|l|l|l|l|}
\hline$s$ & .05 & .1 & .15 & .2 & .25 & .3 & .35 & .4 \\
\hline$s_{o}$ & .089 & .14 & .225 & .355 & .47 & .577 & .585 & .577 \\
\hline$s_{m}$ & -.07 & -.05 & -.035 & -.024 & -.018 & -.013 & -.015 & -.0153 \\
\hline
\end{tabular}

For all values of $s$, the condition $s_{m}<s<s_{o}$ is valid, i.e. the DFIG always operates in a stable range.

\section{CONCLUSION}

The sub-synchronous speed range within which a double fed induction machine, coupled to a wind turbine, operates as a generator is determined in this paper. An approach simpler than the d-q model, namely, the rotor power flow approach, is used in the analysis. Generalized formulae for the generating sub-synchronous speed range are deduced as a function of the machine parameters, as well as the magnitude and phase angle 
of the converter voltage feeding the rotor circuit. The optimum conditions for power generation at sub-synchronous speeds are formulated. Also, the control strategy for a DFIG converter for maximum utilization of wind turbine power is depicted.

The analysis revealed the ability of a DFIG to generate within a wide range of sub-synchronous speeds. The magnitude and phase angle of the rotor injected voltage within which generation occurs are formulated as functions of the rotor speed and machine parameters. Also, the analysis revealed that the induction machine parameters affect the amount of power generated at each rotor speed. The results are plotted in look-up tables so they can be easily applied to any induction machine. Such a system allows the utilization of wind power at low wind speeds, thus leading to higher power harvesting and consequently higher efficiency of wind energy conversion system (WECS). These results should help system designers choose appropriate components for a WECS that will meet the requirements essential for the capability of wider speed range generation.

\section{List of Symbols}

I: phase current

$\mathbf{I}^{*}$ : phase current conjugate

$\mathbf{V}$ : phase voltage

$R$ : resistance per phase

$X$ : leakage reactance per phase at supply frequency

$P_{g}:$ air gap power

$P_{m}$ : mechanical power

$P_{\text {cur }}:$ rotor copper losses

$P_{r}:$ rotor power (slip power)

$P_{1}$ : stator active power

$n_{s}$ : synchronous speed in $\mathrm{rpm}$

$n_{r}$ : rotational speed in $\mathrm{rpm}$

$s:$ slip

$s_{o}$ : slip value above which the flow of $\mathrm{Pg}$ reverses its direction

$s_{i}$ : slip corresponding to the cut-in speed of wind turbine

$s_{m}$ : slip at which maximum $P_{g}$ occurs

$E_{r}$ : rotor induced voltage

$E_{\text {ro }}$ : rotor induced voltage at standstill

$\alpha$ : ratio of converter output voltage to the stand-still rotor induced voltage

$\beta$ : ratio of stand-still rotor leakage reactance to the rotor resistance

$\gamma$ : phase angle between converter voltage and rotor induced voltage

\section{Subscripts}

$s$ : stator values

$r$ : rotor values

$c$ : converter values

\section{REFERENCES}

[1] Thresher R, Robinson M, and Veers P, "The Capture of Wind", IEEE on Power and Energy, Vol. 5, No. 6, pp. 34 -46, Nov./Dec. 2007.

[2] "World Wind Energy Report 2008", World Wind Energy Association, Feb. 2009.

[3] Wu Dingguo, Wang Zhixin, "Modeling and Design of Control System for Variable Speed Wind Turbine in All Operating Region," WSEAS Transactions on Circuits and Systems, pp. 438-443, May 2008.

[4] Badrul H. Chowdhury, Srinivas Chellapilla, "Double-fed induction generator control for variable speed wind power generation," Electric Power Systems Research, Vol. 76, pp. 786-800, 2006.

[5] Hofmann, W.; Okafor, F., "Doubly-Fed Full-Controlled Induction Wind Generator for Optimal Power Utilisation," Proceedings of PEDS Conference, pp. 1-6, 2001.

[6] Saleh, M.A., Issawi A.M., and Iskander M.N., "Double Excited Induction Generators Operating with WECS," Proceedings of The International Conference on Electrical Machines, Lausanne, Switzerland, 18-21, Pt. 3, pp. 1064-1067, Sep. 1984.

[7] Mona N. Eskander, Mahmoud A.Saleh, Mohsen T El-Hagry, "Performance of Double Fed Induction Machine at Sub- and Super-Synchronous Speed in Wind Energy Conversion System" Journal of Power Electronics, Vol. 9, No.4., pp. 575-581, Jul. 2009.

[8] E.H.Lyson, "Introduction to Wind Energy," CWD Consultancy Services Wind Energy Developing Countries, The Netherlands, May 1983.

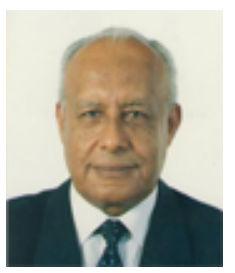

Mahmoud Abdel Halim Saleh was born in Cairo, Egypt on February 28th, 1936. He received B.Sc. degree in Electrical Engineering from Cairo University in 1956 and $\mathrm{Ph} . \mathrm{D}$. in Electrical Engineering from Moscow Energy Institute in 1963. He was a Teaching Assistant in the Department of Electrical Engineering at Alexandria University from 1956 to 1959 . He was an Assistant Professor from 1963 to 1968, an Associate Professor from 1968 to 1973 and a Professor from 1973 to 1982 at the National Research Center, Cairo, Egypt. Then he became a Professor from 1989 to 1996 and an Emeritus Professor from 1996 to the present at the Electronics Research Institute (ERI), Cairo, Egypt. During that period, he was appointed as the Head of the Electrical and Electronics Engineering Research Laboratory and the Chief of the Engineering Research Division in the National Research Center and Director of the Electronics Research Institute, Cairo. He worked (on assignment) as a Lecturer in the Military Technical College of Cairo from 1964 to 1967 and as a Professor in the Military Technical College of Baghdad from 1975 to 1976. Also, he worked as a Senior Regional Advisor on New and Renewable Energy in the United Nations Economic and Social Commission for Western Asia from 1980 to 1981, from 1982 to 1983 and from 1984 to 1998 . He is the Author of more than sixty scientific and technical papers and reports in the fields of Electromechanical Energy Conversion and Renewable Energy Technologies, published in national and international scientific journals and presented at regional, national and international conferences. Dr. Saleh has been a Senior Member of the IEEE since 1970 and a Life Member since 2003.

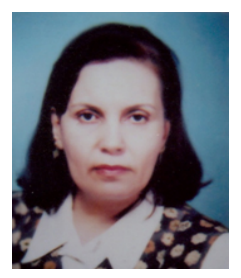

Mona Naguib Eskander obtained the M.Sc. from Cairo University and Ph.D. from Menoufia University in Egypt. She is currently the Head of the Power Electronics \& Energy Conversion Dept. at the Electronics Research Institute in Cairo, Egypt. Her research interests are in the fields of renewable energy (wind, PV and fuel cells), electrical drives, intelligent control and robot manipulators. She has participated in a number of projects in the industrial sector in the field of robot manipulators, mobile robots, illumination, as well as projects in the field of hybrid renewable energy systems. She is a part time professor in Banha Higher Institute of Technology, Banha University, Egypt. She is also the author or co-author of forty scientific papers. 